\title{
Educação para aposentadoria: avaliação dos impactos de um programa para melhorar qualidade de vida pós-trabalho ${ }^{1}$
}

\author{
Education for retirement: assessment of the impacts of a program to improve \\ quality of life after work
Éducation pour la retraite: évaluation des impacts d'un programme visant à améliorer la qualité de vie après le travail
Educación para la jubilación: evaluación de los impactos de un programa para mejorar la calidad de vida después del trabajo

\author{
Lusineide Ferreira Martins ${ }^{2}$ \\ Elisa Silva Borges ${ }^{2}$
}

Recebido em 11/02/2017; revisado e aprovado em 19/04/2017; aceito em 19/04/2017

DOI: http://dx.doi.org/10.20435/inter.v18i3.1496

\begin{abstract}
Resumo: A transição para aposentadoria pode eliciar crises no sujeito, assim o Programa de Educação para Aposentadoria foi desenvolvido a fim de auxiliar os servidores públicos nesse processo. O objetivo do artigo foi de relatar a experiência da implantação deste. Os métodos empregados foram: revisão da literatura, entrevistas, Escala de Mudança em Comportamento de Planejamento em Aposentadoria e Rodas de Conversa. Após avaliação do Programa, houve mudanças nas intenções e comportamentos.
\end{abstract}

Palavras-chave: trabalho; aposentadoria; Programa de Preparação para Aposentadoria.

Abstract: The transition to retirement can elicit crisis in the person, so the Education Program to Retirement was developed to assist public servants in this process. The aim of this is paper report the implementation experience of this program. The employed methods were: a literature review, interviews, Scale of Change in Behavior of Retirement Planning and conversation circles. After evaluating the program, it was found changes in the categories of intentions and behaviors.

Key words: job; retirement; Preparation For Retirement Program.

Résumé: La transition à la retraite peut provoquer des crises au sujet, donc le Programme d’Éducation pour Retraite a été développé pour aider les fonctionnaires publiques à ce processus. Le but de cet article a été de rapporter l'expérience de la mise en œuvre de ce programme. Les méthodes employées étaient: revue de la littérature, des entretiens, des Échelle de Changement en Comportement de Planification en Retraite et de la Roue de Conversation. Après l'évaluation du programme, il a été constaté qu'il y avait des changements dans les catégories d'intentions et des comportements.

Mots-clés: job; retraites; Préparation Pour Le Programme de Retraite.

Resumen: La transición a la jubilación puede provocar crisis en la persona. Así, fue desarrollado el Programa de Educación para la Jubilación para ayudar los funcionarios que se encuentran en este proceso. El objetivo del artículo es relatar la experiencia de aplicación del programa. Los métodos empleados fueron: revisión de la literatura, entrevistas, Escala en el Comportamiento de Planificación de la Jubilación y ruedas de conversación. Después de evaluar el programa, se encontró que hubo cambios en las categorías de intenciones y comportamientos.

Palabras clave: trabajo; jubilación; Programa de Preparación para La Jubilación.

\footnotetext{
${ }^{1}$ Artigo realizado como Trabalho de Conclusão de Curso, na Especialização em Psicologia Organizacional e do Trabalho, na Universidade Católica Dom Bosco (UCDB).

${ }^{2}$ Universidade Católica Dom Bosco (UCDB), Campo Grande, Mato Grosso do Sul, Brasil.
} 


\section{INTRODUÇÃO}

O trabalho, no setor público, proporciona estabilidade quanto ao emprego, o que faz com que os servidores permaneçam na mesma instituição, muitas vezes, por trinta anos ou mais. Com isso, a identidade do sujeito, os vínculos e papéis sociais estão extremamente imbricados à vida laboral.

A aposentadoria se constitui o marco de transição de uma vida com rotina atrelada ao trabalho, para uma nova etapa em que essas variáveis podem ser perdidas, o que pode eliciar crises. Os Programas de Educação para Aposentadoria podem ser instrumentos facilitadores nesse processo.

Este artigo teve como objetivo relatar a experiência da implantação do Programa de Educação para Aposentadoria (EPA) implantado para os servidores públicos de uma autarquia federal. A Gerência em que foi implantado o projeto é constituída por 325 servidores, sendo que 71 já possuem o direito à aposentadoria, portanto imprescindível um programa como o EPA para auxiliar esses servidores nessa transição.

\section{A IMPORTÂNCIA DO TRABALHO NA FORMAÇÃO DA IDENTIDADE}

O trabalho é um dos pilares da constituição da identidade dos sujeitos, pois é por meio dele que as pessoas se colocam diante da sociedade, criam redes e constroem conhecimento. É pelo trabalho que as pessoas têm a oportunidade de serem reconhecidas pelos seus méritos e encontrar a forma de se colocar no mundo (DEJOURS, 2010).

O trabalho pode ser fonte de prazer e sofrimento, dependendo das relações e condições de trabalho proporcionadas ao trabalhador. O trabalho se constitui fonte de satisfação das necessidades psíquicas e de vivências de prazer quando há "[...] uma negociação bem sucedida entre desejos inconscientes do sujeito e a realidade" (MENDES, 1995, p. 36), quando há identificação com as tarefas, com os valores e práticas da organização, percepção de sentido no que se faz e possibilidade de exercer a criatividade, entretanto nem sempre o trabalho permite a sublimação, causando sofrimento pelo não atendimento das necessidades psíquicas.

Nessa situação, pode haver algum espaço para a inteligência prática ou processos de reconhecimento simbólico, que possibilitam contingências de trabalho mais agradáveis, configurando o sofrimento criativo que também pode levar à obtenção de prazer. Quando não há espaço para esses processos, enfrenta-se o sofrimento por meio de mecanismos de defesa, de forma individual ou coletiva, gerando somatizações, dificuldades de relacionamento e adoecimento (DEJOURS, 1987).

Por outro lado, não trabalhar, como no caso do sujeito se aposentar, pode privar o sujeito de um espaço de autoexpressão, o que também pode ser danoso à saúde. A questão não é escolher entre trabalhar e não trabalhar, mas qual trabalho exercer (DEJOURS, 2004). Este autor propõe "atividade coordenada útil" (DEJOURS, 2004, p. 448) como definição de trabalho, ou seja, uma ocupação com um propósito, que envolva um coletivo e que tenha valor técnico, social ou econômico. Isso não se aplica ao lazer (falta-Ihe o critério de utilidade), mas se aplica a atividades associativas, políticas, artísticas e educativas. Portanto, ao se aposentar de um trabalho formal, existem várias formas de se obter a gratificação que aquele proporcionava. 


\section{A TRANSIÇÃO PARA APOSENTADORIA}

A aposentadoria é um momento de mudança na vida das pessoas, sendo esse período resultante da maneira como foi organizada a vida, a importância dada ao trabalho e os vínculos com o sistema social. Cada pessoa investe mais ou menos na vida profissional segundo suas necessidades. A aposentadoria é o momento de reestruturação da identidade pessoal e estabelecimento de novos pontos de referência (ZANELLI; SILVA, 1996).

A vivência dessa etapa é potencialmente geradora de crise, provocando sentimentos de inutilidade, vazio e baixa autoestima, entretanto isto pode ser modificado com o engajamento contínuo com a vida (FONSECA, 2011).

A cultura capitalista tem uma conduta de reprovação às pessoas que não desempenham uma função "produtiva", conforme Bruns e Abreu (1997), o envelhecer pode relacionar-se ao descarte do ser humano, daquele que perdeu a "utilidade". Além disso, sinais de declínio biológico, a saída dos filhos de casa para constituírem suas próprias famílias e a perda dos progenitores são mudanças importantes nesse momento da vida (SOARES et al., 2007).

Além disso, trabalhadores muito comprometidos com o trabalho enfrentam dificuldades para deixar a empresa ao se aposentar, pois, conforme Cude e Jablin (1992), esses trabalhadores tornam o trabalho um meio de desenvolver suas potencialidades, impactando em melhores resultados e reconhecimento social pelo trabalho, por outro lado, esses mesmos esforços dificultam deixar a empresa na aposentadoria. E o trabalhador que relaciona o seu trabalho apenas como meio provedor de subsistência tem maiores chances de vislumbrar a aposentadoria como uma fase de novas possibilidades (BOTH, 2004).

França et al. (2013) também apontam que a percepção de trabalhadores sobre a autonomia, flexibilidade de horários e políticas empresariais voltadas para o envelhecimento são fatores relevantes para o adiamento da aposentadoria, enquanto que estresse laboral e problemas de relacionamentos são fatores preditivos para a decisão pela aposentadoria. Além disso, fatores como o desejo de realizar uma atividade diferente (voluntariado, religião, realizar cursos), idade avançada, problemas com a própria saúde ou de um familiar também influenciam a decisão pela aposentadoria.

Portanto a aposentadoria é um processo complexo, particular e heterogêneo. Relaciona-se, muitas vezes, com a velhice ou à inatividade, podendo impactar negativamente na qualidade de vida do indivíduo e provocar uma crise identitária. Pode ainda representar uma fase de recomeço, com novas possibilidades prazerosas e maior bem-estar (VARELLA, 2013). O que poderá influenciar essa vivência será a trajetória de vida, as relações sociais, bem como o grau de centralidade do trabalho em sua vida (SANTOS, 1990; FIGUEIREDO, 2005).

O instrumento que pode auxiliar nessa transição é o Programa de Educação para Aposentadoria, no apoio da construção de novas escolhas e projetos de vida, ao redimensionamento das imagens vinculadas à condição de aposentado e à reflexão sobre a relação identidade-trabalho (SELIG; VALORE, 2010).

Além disso, as ações de preparação para aposentadoria devem estar respaldadas no autoconhecimento, no reconhecimento de potencialidades e limitações, bem como auxiliar na prevenção de possíveis conflitos e no apoio para o planejamento do seu futuro (ZANELLI; SILVA; SOARES, 2010). Temas como planejamento financeiro, saúde, educação, atividades de trabalho remuneradas e voluntárias, relacionamento familiar e social e atividades culturais e de lazer são sugeridos por França e Soares (2009). 
Dessa forma, considerando a Portaria SRH n. 1.261, de 5 de maio de 2010, publicada pelo Ministério do Planejamento, Orçamento e Gestão, por meio da Secretaria de Recursos Humanos, que objetiva instituir a Política de Atenção à Saúde do Servidor - PASS (Portaria n. 1.261, 2010), e a Política Nacional do Idoso, amparada pelo artigo 230 da Constituição Federal e regulamentada pela Lei 8.842 (Estatuto do Idoso) de 4 de janeiro de 1994, ficou instituído, como uma das políticas da Autarquia Federal deste estudo, o EPA a ser implementado em suas Gerências.

\section{METODOLOGIA DO PROGRAMA}

Para elaboração do projeto do EPA, inicialmente, foi realizada uma revisão dos documentos formais da Política Nacional de Qualidade de Vida da Autarquia, além da realização de leitura livros, artigos e teses que tratam de assuntos como trabalho, aposentadoria e envelhecimento.

O Programa foi construído a partir das entrevistas realizadas com os servidores, em processo de aposentadoria, sendo descartadas aquelas que os servidores desistiram de participar do Programa, além da revisão da literatura e da aplicação da Escala de Mudança em Comportamento de Planejamento em Aposentadoria (EMPCA). A programação foi definida no início do EPA, tendo sofrido algumas a alterações conforme necessidades apresentadas.

$\mathrm{Na}$ entrevista preliminar, foram abordados pontos a respeito da trajetória profissional do servidor no INSS, da percepção do trabalho atualmente, como tem vivenciado o processo de aposentadoria, qual o sentido de se aposentar, quais suas dúvidas, angústias, planos.

O EMPCA, além da aplicação no início do Programa, foi replicado no final para realização de um feedback, com a finalidade de o grupo identificar e debater as mudanças. A Escala EMPCA, instrumento autoaplicável, é dividida em 15 itens a serem assinalados à opção mais adequada ao participante, os quais se relacionam a comportamentos favoráveis à adaptação para aposentadoria, conforme estudos de Leandro-França e Murta (2014).

Os itens da Escala referiam-se a categorias de intenções de comportamentos: a) Ocupação, que consiste em se engajar em atividade de lazer, hobbies, religião, voluntariado e novos focos profissionais. b) Cuidados com a Saúde, a partir de check-up médico, atividade física e alimentação saudável. c) Rede Social, que consiste em investir nos relacionamentos com amigos, familiares e experiências entre grupos. d) Planejamento para a aposentadoria. e) Finanças: investimento financeiro e controle de gastos (FRANÇA, 2012).

Essa Escala é baseada no Modelo Transteórico de Mudança de Prochaska e Diclemente (1982), que adota os construtos processos de mudança e estágios de mudança. Os processos de mudança subdividem-se em processo experiencial (tomada de consciência da situação a ser modificada, alívio, reconhecimento dos pontos positivos da mudança, reavaliação dos comportamentos e empoderamento para a mudança) e o processo comportamental (fatores que levam ao comportamento-problema, substituição de comportamento por um mais apropriado, confiança na mudança, planejamento de recompensa para reforçar o comportamento adequado).

O processo de mudança é dividido em estágios: pré-contemplação (ausência de consciência do problema e resistência à mudança), contemplação (tomada de consciência sobre a necessidade de mudança, com sentimentos ambíguos quanto aos prós e contra da mudança), preparação (planejamento da mudança), ação (engajamento em novos comportamentos), permanência (manutenção do comportamento por pelo menos seis meses) e recaída (retrocessos que naturalmente acontecem na passagem dos estágios). 
A Escala de resposta, com seis opções, ancora-se nos estágios de mudança: 1) não estou interessado nisso (pré-contemplação), quando o indivíduo não considera que tem um problema ou está resistente/desinteressado à mudança; 2) venho pensando em fazer algo sobre isso (contemplação), a pessoa se conscientiza, pensa sobre a mudança, mas ainda está ambivalente; 3) estou decidido a fazer algo nesse sentido (preparação), quando há a determinação de buscar ajuda e se comprometer com a mudança; 4) comecei a fazer, mas parei (recaída); 5) comecei a fazer há pouco tempo (ação), com engajamento em algumas atividades específicas; 6) já faço isso há bastante tempo (manutenção), há permanência na mudança há pelo menos seis meses.

A coordenação dos temas psicológicos ficaram sob responsabilidade de um psicólogo e a realização dos temas informativos foram articuladas em parcerias com profissionais e instituições, tendo sempre em vista o formato de Rodas de Conversa. As Rodas de Conversa são muito utilizadas em projetos de pesquisa e intervenção em psicologia, pois, conforme Mello et al. (2007), esse método prioriza a discussão de temas selecionados para atingir objetivos de pesquisa, em um processo dialógico, no qual as pessoas têm oportunidade de realizar elaborações, com possibilidade de troca de experiências.

As Rodas de Conversa são preconizadas por oficinas de intervenção psicossocial com o objetivo de abrir um espaço de debate sobre questões cotidianas, por meio de técnicas de dinamização de grupo. A escolha dos instrumentos fica a critério do coordenador do grupo, mas quem define, vivencia e direciona a técnica para os objetivos é o grupo. É importante ressaltar que essas Rodas de Conversa não possuem caráter terapêutico, sendo que a manifestação dos participantes é livre, sem revelações íntimas (AFONSO; ABADE, 2008).

Além disso, as Rodas de Conversa foram escolhidas com método, pois possibilita encorajar a auto-avaliação, a tomada de decisão, o estabelecimento de planos de ação, a prevenção de recaídas e a troca de apoio social entre os participantes, conforme preconiza o modelo Transteórico de Mudança (PROCHASKA; DICLEMENTE, 1982).

A análise dos resultados utilizou-se da abordagem qualitativa e teve como base os resultados da segunda aplicação do EMPCA, além dos relatos das participantes do encontro de devolutiva dos resultados. Para comparação dos resultados do instrumento EMPCA, foram considerados apenas os questionários das pessoas que permaneceram no EPA.

\section{ENTREVISTAS E EMPCA}

Enquanto projeto piloto, foram escolhidos 19 servidores públicos lotados em atividades administrativas. Entretanto houve desistência de 11 pessoas, por não terem interesse pela aposentadoria em curto prazo, excesso de trabalho, além de desmotivação com a Instituição pelo descrédito com as perdas salariais decorrentes da aposentadoria, sendo o Programa interpretado como uma medida paliativa da política de aposentadoria da Autarquia.

Permaneceram, portanto, no EPA, oito pessoas, sendo todas mulheres, na faixa etária entre 50 e 65 anos de idade, a maioria com 30 anos de tempo de serviço na Autarquia. A previsão para se aposentarem foi, em média, de dois anos, devido à dificuldade decorrente da perda salarial pós-aposentadoria, identificação com as tarefas, o status de chefia e a rede social proporcionada pelo trabalho. Outros fatores que predominaram foram familiares, como a necessidade de cuidar de pais doentes, ou por problemas com a própria saúde. Cude e Jablin, (1992) e França et al. (2013) confirmam que a questão financeira, o forte vínculo com o trabalho e as questões familiares influenciam na decisão de se aposentar. 
Percebeu-se que, ao serem questionadas sobre o sentido de se aposentar, as pessoas relacionavam a ter mais liberdade e maior disponibilidade de tempo para cuidar de parentes próximos, como pais, netos, porém algumas relataram dificuldades no sentido da redução da remuneração. Declarações contraditórias como estas são discutidas por Zanelli, Silva e Soares (2010) como comuns na fase de transição, pois, independente da relação que as pessoas têm com o trabalho, a aposentadoria tende a gerar sentimentos ambíguos, com sensação de liberdade e, ao mesmo tempo, ansiedade frente ao desconhecido.

Os temas escolhidos nas entrevistas foram principalmente referente à legislação, reorganização da rotina ("o que fazer?") e trabalho voluntário. Após análise da EMPCA, verificou-se a necessidade de se trabalhar temas relacionados a cuidados com a saúde, ampliação da rede social, novas possibilidades de ocupação, investimentos financeiros e projetos para aposentadoria.

Com base nesse material, foram elencados temas psicológicos envolvidos na aposentadoria- identidade, autoimagem, reorganização dos papéis familiares, redefinição da rotina, redes sociais, resgate de projetos abandonados e elaboração de um novo script de vida- bem como temas informativos- trabalho voluntário, legislação de aposentadoria do servidor público, prevenção em saúde, administração financeira e empreendedorismo.

\subsection{Os encontros}

1ㅇ Encontro - Houve uma explicação geral de como funcionaria o EPA, acordos foram estabelecidos e os participantes assinaram o Termo de Consentimento Livre e Esclarecido a fim de permitirem relatar a experiência do EPA. A partir daí, foi aplicada a Dinâmica da Pizza, para identificação de temas de interesse dos participantes (namoro, política, trabalho, por exemplo) e o grau de importância de cada escolha, com o objetivo de verificar o espaço que o trabalho ocupa na vida das pessoas. O debate girou em torno da vinculação com o trabalho e os novos papéis a serem exercidos após a aposentadoria, bem como a importância do investimento em outros temas elencados e a formação de novas redes sociais fora do trabalho. O maior investimento na família confirma as informações levantadas nas entrevistas e no EMPCA. Enquanto que a dedicação ao trabalho foi relacionada ao tempo de oito horas diárias trabalhadas, que determina o desinvestimento nas demais áreas de interesse.

2o Encontro - O objetivo deste encontro foi trabalhar autoimagem e autoestima, e foi utilizada a dinâmica "Auto Propaganda". Cada integrante fez uma propaganda de si mesma e, na apresentação ao grupo, as colegas podiam fazer considerações. Essa dinâmica permitiu a identificação das próprias qualidades, além de a complementação das colegas ter auxiliado na coesão do grupo.

3을 Encontro - Neste encontro, foi realizada a dinâmica do Mapa da Rede Social para as participantes identificarem as pessoas de maior importância em sua vida. A ênfase da discussão foi em relação ao investimento de relações fora do trabalho para facilitar a transição para a aposentadoria, bem como o resgaste de amizades que, com o tempo, foi se distanciando. Outro foco de debate foi o papel da tecnologia e das redes sociais nas relações, que substituíram as cartas enviadas por correio e o contato físico, bem como a resistência em se usar essas ferramentas. Na segunda dinâmica, foi proposto que as participantes identificassem, por meio de símbolos, pessoas e instituições importantes para o seu crescimento, assim como os frutos decorrentes dessas relações. Amigos pessoais, familiares e a escola formal foram destaque na 
escolha das participantes, e os frutos dessas relações foram amor, bons valores e educação. No final, discutiu-se que as ferramentas cibernéticas podem ser instrumentos para contatos com as pessoas, sendo utilizadas para maior proximidade e resgate de pessoas afastadas.

4을 Encontro - Este encontro teve como objetivo trabalhar o papel do servidor na sociedade enquanto trabalhador e, após a aposentadoria, tendo sido apresentado o filme "O verdadeiro significado de ser rico" para disparar o tema. Enquanto servidoras, foram destacadas as dificuldades enfrentadas no dia a dia, em relação ao público alvo, que tenta burlar algumas regras para receber benefícios. Foi trabalhado que o papel do servidor não é apenas ajudar o usuário do serviço a obter direitos, mas também fiscalizar, para garantir direitos a quem realmente necessita. Com a aposentadoria, apareceu no grupo a possibilidade de realização do trabalho voluntário. Além disso, emergiu a angústia frente às prováveis responsabilidades delegadas pela família após a aposentadoria. A partir disso, o grupo optou por substituir o tema de trabalho voluntário por reorganização da rotina.

5 ㅇ Encontro- Foi aplicada a técnica "Gastonograna", que consiste em quatro quadrantes a serem preenchidos por atividades que "eu gosto e faço", "gosto e não faço", "não gosto e faço" e "não gosto e não faço". A discussão teve como foco a dificuldade em colocar limites para responsabilidades que a família elege quando a aposentadoria acontece. Foram debatidas alternativas para organizar a rotina de uma maneira que seja possível ter lazer, descanso e fazer aquilo que gosta. Outro ponto de discussão foi a idealização da aposentadoria, enquanto uma fase em que tudo poderá ser feito, em termos de viagens, leitura, descanso. Entretanto, novas responsabilidades são incorporadas, e os rendimentos vão diminuir com a aposentadoria, o que inviabiliza a realização de muitas atividades desejadas. Após a reflexão, o grupo concluiu que deve pensar na aposentadoria de acordo com a realidade de cada uma.

6 Encontro - O tema deste encontro foi Saúde na Terceira Idade, realizado por um enfermeiro, que debateu o significado de sexualidade: relações sexuais, mudanças hormonais e fisiológicas que geram impactos na saúde física e mental, bem como nas relações sociais. O encontro foi uma oportunidade para as integrantes tirarem dúvidas sobre a menopausa, osteoporose, sobre os efeitos das atividades físicas e das mudanças nos hábitos alimentares para a prevenção desses problemas.

7 ㅇ Encontro - Neste encontro, foi solicitado o preenchimento de uma tabela com atividades a serem realizadas, após a aposentadoria, todos os dias da semana. Houve interesse por atividades físicas, em sua maioria, o que pode ser reflexo do encontro anterior, além de atividades educativas, de lazer e trabalho voluntário. As motivações pelo voluntariado foram a evitação do tédio e o preenchimento do vazio deixado pelo trabalho. Foi debatido como o trabalho organiza a rotina, como por exemplo, determina que as pessoas se arrumem para o trabalho, os horários livres para dedicação à família e ao lazer. Por isso, a importância de se planejar a nova rotina, no período da aposentadoria, levando em consideração a ausência do fator trabalho.

8 o Encontro - Neste encontro, a servidora do Recursos Humanos, responsável pelos trâmites burocráticos para aposentadoria dos servidores, fez uma Roda de Conversa com o grupo para explicar o que a legislação prevê em termos de regras de aposentadoria. Muitas dúvidas foram sanadas e, no final, houve um debate sobre as perspectivas futuras de mudanças na legislação, principalmente no que se refere à redução dos ganhos de quase $40 \%$ dos rendimentos.

9 o Encontro - O tema trabalhado foi sobre as expectativas e medos em passar mais tempo com a família. A questão do aumento de atividades típicas da mulher (casa, cuidado com idosos 
e netos) foi o foco maior da discussão. A reflexão sobre os papéis de gênero e aposentadoria girou em torno de como, por um lado, a mulher pode encontrar pontos referenciais de identificação que extrapolam o circuito formal de trabalho, amenizando possíveis efeitos adversos da aposentadoria (MORAGAS-MORAGAS, 1998; SANTOS 1990). Por outro lado, foi abordada a desigualdade de gênero em relação ao excesso de responsabilidades, o que pode ser amenizado por meio do diálogo, na tentativa de diminuir essa disparidade.

10 ○ Encontro - O tema Empreendedorismo foi debatido com uma convidada do Serviço Brasileiro de Apoio às Micro e Pequenas Empresas (SEBRAE) para sanar expectativas das participantes que pretendiam abrir um negócio próprio ou para um filho. A convidada do SEBRAE explicou alguns passos importantes, antes da abertura de um negócio, dentre eles, a clientela, o espaço de produção, os custos, fornecedores, logística, viabilidade econômica, equipamentos necessários e planejamento.

11 Encontro - A Roda de Conversa deste encontro foi sobre Economia Doméstica para preparar as servidoras em relação à redução dos rendimentos salariais decorrentes da aposentadoria. Inicialmente, foi passado o filme "A História das Coisas", que trouxe a reflexão do consumo responsável e mudanças de hábitos no sentido de reaproveitar, reciclar e reduzir o consumo. Num segundo momento, houve a troca de experiências a respeito das estratégias para cortar gastos e planejar a aposentadoria, além da apresentação de aplicativos de celulares para utilização de planilhas de controle de gastos, bem como um aplicativo que mostra lojas que estão sofrendo processo trabalhistas por empregar mão de obra escrava, para evitar consumir nesses lugares.

12 을 Entro - Iniciou-se, neste encontro, o fechamento do Programa, sendo realizada a aplicação do EMPCA para verificar se houve mudança de comportamentos das participantes do Programa. Além disso, foi solicitado que as integrantes elencassem os pontos positivos e negativos do EPA. A descrição dos resultados da avaliação do programa está dividida com base nas categorias de intenção de comportamentos (FRANÇA; MURTA, 2014).

\section{ANÁLISE E DISCUSSÃO DOS RESULTADOS}

\subsection{Saúde}

O Programa contemplou o tema saúde, com o apoio do profissional convidado, além do debate nos encontros sobre reorganização da rotina e dos papéis familiares, pois organizar o tempo e limitar o excesso de responsabilidades delegadas pela família, após a aposentadoria, são fatores importantes para a manutenção da saúde. Em âmbito geral, o Programa, ao apoiar na transição do trabalho para a fase de aposentadoria, ao debater as novas identidades, autoimagem e autoestima e as questões de gênero, foi importante instrumento para a saúde física e mental das participantes.

Destaca-se que muitas das participantes já tinham comportamentos saudáveis, como consultas a médicos regularmente, mudanças na alimentação e a prática de atividades físicas, mesmo assim, sugeriram aprofundar temas relacionados à saúde por meio do EPA.

A pro atividade das participantes na busca dos cuidados à saúde, confirma uma revisão na literatura realizada por França (2012), em que mostra que as mulheres em transição para aposentadoria são ativas na busca por informações e serviços voltados para saúde, principalmente as mulheres com maior grau de instrução, perfil apresentado pelas participantes do Programa. 


\subsection{Investimentos financeiros}

Sobre investimentos no futuro, observou-se que as participantes ao longo da vida, fizeram alguns investimentos, mas não específicos para aposentadoria. Depois do Programa, relataram que perceberam que deveriam fazer uma nova adequação dos recursos financeiros para a aposentadoria e solicitaram convidar algum palestrante para orientar qual o melhor investimento na transição para aposentadoria. Portanto o EPA despertou a necessidade de planejamento das finanças para o contexto da aposentadoria, pois, na entrevista, o discurso era queixoso, sem a adoção de novos hábitos de consumo com vistas à aposentadoria.

\subsection{Rede social}

A respeito da rede social, o investimento de tempo na convivência familiar já era alto e manteve-se. Um ponto de discussão no grupo foi o exemplo real do processo de adaptação de aposentadoria de um dos familiares das participantes, que impactou negativamente as relações familiares, o que enriqueceu as reflexões sobre como lidar com estas dificuldades.

A dedicação nas relações sociais tiveram como foco maior a família e amigos antigos, mas nota-se a intenção de ampliar essas redes após a aposentadoria, sendo que o EPA auxiliou a reflexão da importância desse investimento.

Aprofundar as relações sociais é um fator importante para o bem-estar na aposentadoria, pois como mostram os estudos de França (2009), ao analisar os preditores sociais nas atitudes em face da aposentadoria de 517 altos executivos do Brasil e da Nova Zelândia, concluiu que, quanto mais positiva for a influência da família e dos amigos, maior será a importância dos ganhos atribuídos na aposentadoria em ambas as nacionalidades.

\subsection{Ocupação}

Esse tema foi escolhido para aprofundamento do debate para verificarem possibilidades de espaços de atuação. No que se refere à ocupação, investir mais tempo em lazer e hobby, houve algumas evoluções, pois as pessoas começaram, após o Programa, a dedicarem mais ao lazer e saíram da fase de contemplação para a decisão de ter um hobby.

Notou-se, ao final do EPA, aumento de pessoas desinteressadas em realizar cursos na área de atuação ou com perspectivas de uma segunda carreira, o que é indício de que as participantes não pretendem continuar trabalhando, mas investir em outras alternativas de ocupação.

O desinvestimento na carreira atual e o avanço em estágios de mudanças na categoria ocupação, pós-aposentadoria, mostra a transição do papel do trabalho na constituição da identidade profissional, em que o sujeito aprofunda seu autoconhecimento para descobrir novas possibilidades ou resgatar velhos hábitos. A transição da identidade de trabalhador para aposentado pôde ser trabalhada no primeiro encontro (o papel do trabalho na vida das participantes), no quarto encontro (papéis sociais) e na discussão sobre a reorganização da rotina.

Outro aspecto importante da transição para aposentadoria é o fato de as servidoras passarem de profissionais que promovem direitos sociais e fiscalizam situações de fraude, para prováveis donas de casa, cuidadora de idosos e crianças. As atividades domésticas e de cuidadoras demarcam a questão de gênero envolvida na distribuição de tarefas entre aposentados homens e mulheres, pois ainda há uma predominância em nossa cultura de que estes papéis 
ficam a cargo das mulheres. Durante o Programa, foram debatidos esses papéis atribuídos pela família e como lidar com eles, na tentativa de se ter mais igualdade de gênero e colocar limites a essas imposições.

A respeito de fazer trabalhos voluntários, não houve grandes mudanças, pois as pessoas estão pensando fazer ou já decidiram começar. Carlos et al. (1999) defende que a aposentadoria traz impactos à identidade, pois a identidade de trabalhador é referenciada ao pertencimento a determinado grupo de trabalho e à carga emocional desse vínculo, além dos prestígios, qualificação profissional e status social. Mesmo a aposentadoria significando a perda do papel profissional, muitas vezes, mantém-se um vínculo simbólico com tudo que está relacionado ao trabalho. Além disso, buscam-se novos trabalhos, muitas vezes voluntários, na tentativa de permanecer reconhecido socialmente enquanto sujeito ativo, simbolizado como oposto à morte e à segregação social. Além disso, Dejours (2004) defende que o trabalho voluntário pode ser fonte de saúde, enquanto "atividade coordenada útil".

Sobre práticas religiosas, o tema não foi debatido no Programa, porém notou-se nessa categoria um declínio nessas práticas. A angústia apresentada frente à reorganização da rotina, após a aposentadoria, pôde ser amenizada, após o enfrentamento do desconhecido, por meio do EPA, o que tornou as participantes protagonistas desse processo e menos ansiosas, portanto, como discute Duarte (2009), quando os sujeitos se preparam para a aposentadoria, a transição é vivenciada de maneira mais tranquila.

\subsection{Projetos para aposentadoria}

A respeito de projetos para aposentadoria, houve mudanças de algumas participantes que pensavam sobre isso e, depois do Programa, passaram para o estágio de decisão. As demais permaneceram no mesmo estágio de recusa e de contemplação, outras já estavam decididas a fazer isso.

Ao serem questionadas sobre quais projetos teriam, percebeu-se que pretendem fazer trabalhos voluntários, investir nos cuidados preventivos à saúde e no lazer. Ter um hobby também foi manifestado pelas participantes, outras relataram que ainda precisam descobrir algum ou não têm nenhum interesse no momento.

O projeto de vida na aposentadoria vai depender da relação que o sujeito construiu com o trabalho ao longo da vida. Santos (1990) classificou três tipos principais de vivências de aposentadoria, sendo uma delas a aposentadoria recusa, caracterizada pela dificuldade de vincular outras atividades que não o trabalho aos projetos de aposentadoria, pois o trabalho é a principal fonte de prestígio, poder, engajamento e confronto do conflito existencial, sendo que o momento da aposentadoria pode gerar crises.

A aposentadoria como sobrevivência, quando o sujeito investe no trabalho, muitas vezes, para sair de uma condição financeira precária, sendo o trabalho supervalorizado e não percebido como desperdício. Nessa condição, os projetos de aposentadoria não se vinculam a descanso e tempo para si mesmo. Por último, a aposentadoria liberdade, vivenciada como um momento merecido e de maior liberdade, com investimento em outras atividades não vinculadas ao trabalho. Pessoas com essa perspectiva constroem suas identidades baseadas não apenas no papel profissional, mas também em outras fontes de engajamento, outras motivações e papéis sociais.

INTERAÇÕES, Campo Grande, MS, v. 18, n. 3, p. 55-68, jul./set. 2017. 
Os encontros do EPA favoreceram a reflexão dos significados do trabalho e da aposentadoria, possibilitando ressignificações e apresentação de novas escolhas para a aposentadoria. Alguns avanços foram percebidos, mas deve-se considerar que a transição da identidade de trabalhador para aposentado é um processo multideterminado, e o Programa é um apoio nessa fase.

\subsection{Pontos positivos e negativos do EPA}

No balanço do Programa, foi avaliado como positivo o formato do grupo em Rodas de Conversa pela oportunidade de ouvir as colegas, compartilhar experiências em um clima descontraído, além de se sentirem ativas nesse processo. Também os temas sobre ocupação foram destaque, pois o Programa possibilitou pensar sobre a programação de atividades, após aposentadoria, pois, antes, muitas nem pensava sobre isso, além da importância em se colocar limites nos familiares para conseguirem ter descanso e lazer. O encontro sobre legislação foi destacado pela oportunidade de tirarem suas dúvidas para se planejarem.

No geral, os temas foram considerados pertinentes para o conhecimento e reflexão sobre a aposentadoria, modificando a percepção das participantes, algumas relatando que irão se planejar para se aposentar. Como pontos negativos do programa, destacaram a importância de se reservar um tempo maior dos encontros informativos, para aproveitarem a oportunidade de tirar as dúvidas.

O limite de uma hora dos encontros foi acordado com o grupo e as chefias, algo que pode ser revisto. A distância do local das reuniões, para quem trabalhava em outro prédio, foi outro ponto levantado, além falta de orçamento para contratar profissionais para as Rodas de Conversa, o que ocasionou dificuldades para trazer convidados para debater os temas. Outro aspecto levantado foi a vinculação da percepção do envelhecimento vinculado à aposentadoria, o que deverá ser mais bem debatido nos próximos encontros.

A associação da aposentadoria ao envelhecimento é debatido por Zanelli, Silva e Soares (2010), como um dos sentimentos ambíguos relacionados à aposentadoria, além de sentimentos de insegurança e dúvida pelo vazio decorrido da falta do trabalho.

Esses autores sugerem fortalecer os aspectos positivos da aposentadoria enquanto um momento de descanso, a disponibilidade de tempo maior com a família e amigos, a descoberta de novos interesses, as possibilidades de impor outro ritmo de vida primado pela qualidade de vida. Outros temas foram sugeridos para aprofundamento nos encontros seguintes, os quais serão mensais: saúde da mulher, saúde na terceira idade, legislação, trabalho voluntário.

\section{CONSIDERAÇÕES FINAIS}

Realizar o contrato grupal e ter trabalhado a coesão do grupo foi fundamental para fortalecer o vínculo entre as participantes e conduzir o grupo. Tudo isto fez com que a ansiedade das participantes diminuísse, permitindo a troca de experiências e tornando o tema da aposentadoria menos assustador ao longo dos encontros.

Destaca-se, ainda, que o formato em Rodas de Conversa possibilitou avançar nos estágios de mudança nas categorias de intenção de comportamento, pois permitiu reflexão, autoavaliação e trocas de experiências. Além disso, a preparação para a aposentadoria foi tratada de forma articulada para promover o bem-estar, destacando as reflexões sobre a transição da identidade 
de trabalhadora promotora de direitos sociais para aposentadas com direitos a uma nova rotina de autocuidados, lazer, hobbies, ampliação das redes sociais, bem como novas ocupações, dentro das possibilidades familiares e financeiras.

No que se refere à parte financeira, a postura de revolta, relacionada à perda de benefícios decorrente da aposentadoria, modificou-se para uma postura de enfrentamento do problema, com a consciência da necessidade de se planejar para a futura redução de orçamento, sem desmobilizá-las na busca por manutenção dos rendimentos por meio de órgãos da Justiça.

Sem desconsiderar as singularidades de cada participante e levando em conta que a aposentadoria é um momento de mudança na vida das pessoas, sendo esse período resultante da maneira como foi organizada a vida, a importância dada ao trabalho e os vínculos com o sistema social, o Programa despertou em cada uma a necessidade de se planejar e cuidar dos múltiplos fatores relacionados ao bem-estar na aposentadoria, principalmente ao que se refere ao planejamento financeiro, a promoção de autonomia, ao suporte afetivo e integração social com a família e amigos, no intuito de proporcionar a manutenção da saúde e no despertar para projetos pós-aposentadoria.

\section{REFERÊNCIAS}

AFONSO, Maria Lúcia; ABADE, Flávia Lemos. Para reinventar as rodas: rodas de conversa em direitos humanos. Belo Horizonte: RECIMAM, 2008.

BRASIL. Portaria n. 1.261, de 5 de maio de 2010. Institui os princípios, diretrizes e ações em saúde mental que visam orientar os órgãos e entidades do Sistema de Pessoal Civil - SIPEC da Administração Pública Federal sobre a saúde mental dos servidores. Brasília, DF: Secretaria de Recursos Humanos, Ministério do Planejamento, Orçamento e Gestão, 2010.

. Lei n. 8.842, de 4 de janeiro de 1994. Dispõe sobre a Política Nacional do Idoso, cria o Conselho Nacional do Idoso e dá outras providências. Diário Oficial da República Federativa do Brasil, Brasília, DF, 5 jan. 1994.

BOTH, Tatiana. Lima. Jubilamento: o interdito de uma vida de trabalho e suas repercussões na velhice. 2004. 98 f. Dissertação (Mestrado em Psicologia Social e Institucional) - Universidade Federal do Rio Grande do Sul, Porto Alegre, RS, 2004.

BRUNS, Maria Alves de Toledo; ABREU, Antonio Suarez. O envelhecimento: encantos e desencantos da aposentadoria. Revista da ABOP, v. 1, n. 1, p. 5-33, 1997.

CARLOS, Sergio Antonio et al. Identidade, aposentadoria e terceira idade. Est. Interdiscipl. Envelhec., Porto Alegre, v. 1, p. 77-89, 1999.

CUDE, Roger L.; JABLIN, Frederic M. Retiring from work: the paradoxical impact of organizational commitment. Journal of Managerial Issues, v. 4, n. 1, 1992, p. 31-45.

DEJOURS, Cristophe. Entre o desespero e a esperança: como reencantar o trabalho? CULT, São Paulo, n. 139, p. 49-53, set. 2010.

. Entre sofrimento e reapropriação: o sentido do trabalho. In: LANCMAN, Selma; Sznelwar, Laerte Idal (Org.). Christophe Dejours: da psicopatologia à psicodinâmica do trabalho. Rio de Janeiro: Fiocruz; Brasília, DF: Paralelo 15, 2004. p. 433-448.

A loucura do trabalho: estudo de psicopatologia do trabalho. Tradução de A.I. Paraguay; L.L. Ferreira. São Paulo: Cortez-Eboré. 1987, 168 p.

DUARTE, Camila Vianna; MELO-SILVA, Lucy Leal. Expectativas diante da aposentadoria: um estudo de acompanhamento em momento de transição. Revista Brasileira de Orientação Profissional, São Paulo, v. 10, n. 1, p. 45-54, jun. 2009. 
FIGUEIREDO, Nara Cristina Macedo de. Interfaces do trabalho voluntário na aposentadoria. 2005. $170 f$. Dissertação. Mestrado em Psicologia Social e Institucional. Universidade Federal do Rio Grande do Sul, Porto Alegre.

FONSECA, Maria Aparecida Mose Ferreira da. A transição do servidor público para a aposentadoria: uma avaliação sobre preocupações do pré-aposentado. 2011. Dissertação (Mestrado Profissional em Avaliação) - Fundação Cesgranrio, Rio de Janeiro, RJ, 2011.

FRANÇA, Cristineide Leandro. Modelo de intervenção breve para planejamento da aposentadoria: desenvolvimento e avaliação. 2012. Dissertação (Mestrado em Psicologia Clínica e Cultural)- Universidade de Brasília (UnB), Brasília, DF, 2012.

FRANÇA, Lucia Helena de Freitas Pinho. Influências sociais nas atitudes dos 'Top' executivos em face da aposentadoria: um estudo transcultural. Revista de Administração Contemporânea, Curitiba, v. 13, n. 1, p. 17-35, jan./mar. 2009.

FRANÇA, Lucia Helena de Freitas Pinho et al. Aposentar-se ou continuar trabalhando? O que influencia essa decisão? Psicologia: ciência e profissão, Brasília, v. 33, n. 3, p. 548-563, 2013.

FRANÇA, Lucia Helena de Freitas Pinho; SOARES, Dulce Helena Penna. Preparação para a aposentadoria como parte da educação ao longo da vida. Psicologia: Ciência e Profissão. Brasília, v. 29, n. 4, p. 738-751, 2009.

LEANDRO-FRANÇA, Cristineide; MURTA, Sheila Giardini. Fatores de risco e proteção na adaptação à aposentadoria. Psicologia Argumento, Curitiba, v. 32, n. 76, p. 33-43, jan./mar. 2014.

MÉLLO, Ricardo Pimentel et al. Construcionismo, práticas discursivas e possibilidades de pesquisa em psicologia social. Psicologia \& Sociedade, Porto Alegre, v. 19, n. 3, p. 26-32, set./dez. 2007.

MENDES, Ana Magnólia Bezerra. Aspectos psicodinâmicos da relação homem-trabalho: as contribuições de C. Dejours. Psicologia: Ciência e Profissão, Brasília, v. 15, n. 1-3, p. 34-38, 1995.

MORAGAS-MORAGAS, Ricardo. Gerontología Social: envejecimiento y calidad de vida. 2. ed. Barcelona: Herder, 1998. 304p.

PROCHASKA, James; DICLEMENTE, Carlo. Transtheoretical therapy: toward a more integrative model of change. Psychoterapy: teory, research, and practice, v. 19, p. 276-288, 1982.

SANTOS, Maria de Fátima de Souza. Identidade e aposentadoria. São Paulo: EPU, 1990, 80 p.

SELIG, Gabrielle Ana; VALORE, Luciana Albanese. Imagens da aposentadoria no discurso de préaposentados: subsídios para a orientação profissional. Cadernos de Psicologia Social do Trabalho, v. 13, n. 1, p. 73-87, 2010.

SOARES, Dulce Helena Penna et al. Aposenta-Ação: Programa de Preparação para Aposentadoria. Estudos Interdisciplinares sobre o Envelhecimento, Porto Alegre, v. 12, p. 143-161, 2007.

VARELLA, Maria das Graças Araújo. Significado do trabalho e aposentadoria: um estudo entre os docentes de uma instituição federal de ensino. 2013, 153 f. Dissertação (Mestrado em Administração Profissional) - Universidade Potiguar (UnP), Natal, RN, 2013.

ZANELLI, José Carlos; SILVA, Narbal. Programa de preparação para a aposentadoria. Florianópolis: Insular, 1996.

ZANELLI, José Carlos; SILVA, Narbal; SOARES, Dulce Helena Penna. Orientação para aposentadoria nas organizações de trabalho: construção de projetos para o pós-carreira. Porto Alegre: Artmed, 2010. 143 p. 


\section{Sobre as autoras:}

Lusineide Ferreira Martins: Mestrado em Psicologia da Saúde, Especialização em Psicologia do Trabalho: Gestão em Qualidade e graduação em Psicologia pela Universidade Católica Dom Bosco (UCDB). Professora do curso de graduação em Psicologia e atua como psicóloga no Serviço Escola de Psicologia da UCDB. Orienta os Trabalhos de Conclusão de Curso nas Pós-graduações em Saúde Mental e Psicologia do Trabalho, na UCDB Virtual. E-mail: lusdemar@ hotmail.com

Elisa Silva Borges: Psicóloga (UFMG), com especialização (UCDB) e mestrado (UFSCar) na área de Saúde do Trabalhador. Trabalhou com projetos de saúde mental e economia solidária por 10 anos e, há três anos, atua na área de qualidade de vida no trabalho, com projetos voltados para os servidores em uma Autarquia Federal. E-mail: tiliciasb@gmail.com 